\title{
Review: patient education interventions improve glycaemic control in adults with diabetes mellitus
}

Ellis SE, Speroff T, Dittus RS, et al. Diabetes patient education: a meta-analysis and meta-regression. Patient Educ Couns 2004;52:97-105.

\section{Do patient education interventions improve glycaemic control in adults with diabetes mellitus?}

\section{METHODS}

\begin{tabular}{|c|c|}
\hline 尼复 & $\begin{array}{l}\text { Data sources: Medline, CINAHL, HealthSTAR, ERIC, Science } \\
\text { Citation Index, PsyclNFO, CRISP, and a database on the } \\
\text { American Association of Diabetes Educators website (http:// } \\
\text { www.aadenet.org). }\end{array}$ \\
\hline & $\begin{array}{l}\text { Study selection and assessment: randomised controlled trials } \\
\text { (RCTs) that were published from } 1990-2000 \text { in English, } \\
\text { evaluated educational interventions in adult outpatients with } \\
\text { diabetes, and reported on glycated haemoglobin }\left(\mathrm{HbA}_{1 \mathrm{l}}\right) \\
\text { concentrations before and after the intervention and at } \geqslant 12 \\
\text { weeks after the intervention. An educational intervention was } \\
\text { defined as any non-pharmacological educational technique that } \\
\text { used physical, intellectual, or psychosocial means to improve the } \\
\text { health of patients with diabetes. }\end{array}$ \\
\hline & Outcomes: glycaemic control ( $\mathrm{HbAl}{ }_{c}$ concentrations). \\
\hline
\end{tabular}

\section{MAIN RESULTS}

21 RCTs (28 educational and 21 control interventions) met the selection criteria. 5 studies had $>1$ intervention group. Study size ranged from 23-320 patients (total 2439 patients). 20 interventions were used in patients with type 2 diabetes, 5 in patients with type 1 diabetes, 2 in patients with either type 1 or type 2 diabetes, and 1 study did not specify the type of diabetes. Follow up ranged from 315 months. Various educational techniques were used (didactic teaching [ $\mathrm{n}=23$ interventions], goal setting $[\mathrm{n}=10]$, goal setting negotiated teaching $[n=12]$, situational problem solving $[n=15]$, cognitive reframing $[\mathrm{n}=4]$, and other unique teaching methods $[\mathrm{n}=13]$ ). In addition, the content of the educational interventions varied (dietary topics $[n=25]$, exercise $[n=18]$, self monitoring of blood glucose $[n=15]$, basic diabetes knowledge $[n=10]$, medication adherence $[\mathrm{n}=8]$, psychosocial topics $[\mathrm{n}=7]$, and other topics $[n=19]$ ). A fixed effects model was used to combine studies. At the first assessment reported after $\geqslant 3$ months of follow up, the intervention group had better glycaemic control than the control group (net $\mathrm{HbA}_{1 \mathrm{c}}$ change $-0.32 \%$, 95\% CI -0.57 to -0.07 ). In separate meta-analyses, the net change was $-0.29 \%$ (CI -0.68 to 0.09 ) at 12 weeks, $-0.49 \%$ (CI -0.92 to -0.05$)$ at 24 weeks, and $-0.33 \%$ (CI -0.76 to 0.10 ) at 52 weeks. The improvement in glycaemic control was statistically significant at the first assessment after the educational intervention and at 24 weeks. Meta-regression analysis showed that interventions using face to face delivery, cognitive reframing, and exercise content were more likely than other intervention types to improve glycaemic control.

For correspondence: Dr T A Ëlasy, Department of Medicine, Veterans Affairs Tennessee Valley Healthcare System, Nashville, TN, USA. tom.elasy@ vanderbilt.edu

Source of funding: not stated.

\section{CONCLUSION}

Patient education interventions, particularly those providing face to face delivery, cognitive reframing, and exercise content, improve glycaemic control in adults with diabetes.

\section{Commentary}

$\Lambda$ Ithough previous reviews of the effects of educational interventions on metabolic control have focused on knowledge, self care management, cardiac risk factor control, and psychological outcomes, the review by Ellis et al provides an important insight into the characteristics of educational interventions associated with improvement in $\mathrm{HbA}_{1 \mathrm{c}}$.

In this well conducted meta-analysis, Ellis et al searched a broad range of databases and, to ensure that quality studies were combined, included only randomised trials. Furthermore, the authors used a previously developed systematic taxonomy ${ }^{1}$ for classifying 9 dimensions of the interventions: setting; delivery; teaching method; content; provider; intensity of the intervention; whether the intervention was tailored to initial assessment; whether there was follow up assessment and modification; and whether basic diabetes education was given to both groups before randomisation.

The authors describe the statistically significant results of the metaanalysis as clinically important but modest. However, they note that the overview findings may underestimate the effects of patient education. Firstly, a $25 \%$ reduction in microvascular complications has been identified for every $1 \%$ decrease in $\mathrm{HbA}_{1 \mathrm{c}_{1}}{ }^{2}$ which underscores the importance of small improvements in net $\mathrm{HbA}_{l c}$ changes. Secondly, in many of the studies included, control groups were given non-trivial initial education sessions. This likely reduces the observed difference between the 2 groups. Finally, variation in timing of $\mathrm{HbA}_{1 c}$ measurements, as recently identified by Norris et al, ${ }^{3}$ may not show the maximal effect because $\mathrm{HbA}_{l c}$ estimates glycaemic control over the previous 8-12 weeks.

Although the measurement of some educational components may be imprecise and some factors contributing to glycaemic control were not assessed, these findings have important implications for those who design, provide, and/or evaluate diabetes education. For researchers, this review highlights the importance of adequately planning and describing educational interventions in evaluative studies.

Deborah A Chyun, RN, PhD, FAHA Yale University School of Nursing New Haven, Connecticut, USA

1 Elasy TA, Ellis SE, Brown A, et al. A taxonomy for diabetes educational interventions. Patient Educ Couns 2001;43:121-7.

2 Intensive blood-glucose control with sulphonylureas or insulin compared with conventional treatment and risk of complications in patients with type 2 diabetes (UKPDS 33). UK Prospective Diabetes Study (UKPDS) Group. Lancet 1998;352:837-53. Erratum: Lancet 1999;354:602.

3 Norris SL, Lau J, Smith SJ, et al. Self-management education for adults with type 2 diabetes: a meta-analysis of the effect on glycemic control. Diabetes Care 2002;25:1159-71. 